\title{
EPIDEMIOLOGY
}

\section{Legionnaires' disease: further evidence to implicate water storage and distribution systems as sources}

\author{
J O'H TOBIN, C L R BARTLETT, S A WAITKINS, G I BARROW, \\ A D MACRAE, A G TAYLOR, R J FALLON, F R N LYNCH
}

In April 1979, 58 employees of a large commercial organisation took part in a golfing tournament in the Midlands. The competitors were drawn from the staff of factories and offices in various parts of the country. Four golfers developed pneumonia in the week after the tournament. Two men, aged 46 and 63 , were admitted to hospital and subsequently recovered. Serological investigations showed that during the course of their illnesses both produced a fourfold rise in antibody to Legionella pneumophila serogroup 1 , as measured by an indirect fluorescence antibody test. Acute-phase sera were not taken from the other two men, but one was found to have a reciprocal titre of 256 on the 41 st day after onset of symptoms. The fourth man has so far remained seronegative when sera have been screened for $L$, pneumophila serogroups 1-6 and various respiratory viral pathogens.

In a large control group of 1987 volunteers employed in various industries in London and the Midlands, only $\left.15\left(0.75^{\circ}\right)_{1}\right)$ had titres of $L$ pneumophila antibody of 32 or greater: 10 had titres of 32 , four of 64 , and one of 128 . Thus two of the golfers were shown to have had Legionnaires' discase and there was strong presumptive evidence for this diagnosis in the third. Five other golfers reported mild respiratory illness after the competition, but late convalescent sera from them were negative for $L$ pneumophila. Forty-two other participants were contacted; one had a titre of 256 and another a titre of 64 in samples taken in July 1979. The possibility that the men may have been infected at the golf club was considered but $L$ pneumophila was not isolated from environmental samples, including water from the sprinkler system at the course. A survey of all the employees at the golf club and several other men who regularly worked in the vicinity showed no serological evidence of exposure to the organism. Work places were also considered as sources of infecition but local investigations found no other cases. Environmental samples, including water from a washing plant in one of the factories, did not yield $L$ pneumophila.

Of the 58 members of the golfing party, the four men with pneumonia had stayed at one hotel, whereas none of 26 who had stayed elsewhere was affected. Although the numbers

Public Health Laboratory Service

J O'H TOBIN, FRCP, FRCPATH, former director, Oxford PHL

C L R BARTLETT, MSC, MFCM, consultant epidemiS A WAITKINS, PHD, senior microbiologist, Liverpool S PHI.

G I BARROW, MD, FRCPATH, director, PHLS Reference Laboratory for Environmental Hygiene, CAMR Laboratory for
Porton Down

A I MACRAE, MD, FRCPATH, consultant virologist, Nottingham PHL

A G TAYLOR, PHD, top grade microbiologist, I)ivision of Microbiological Reagents and Quality Control, CPHL

Department of Laboratory Medicine, Ruchill Hospital, Glasgow

R J FALLON, FRCP, FRCPATH, consultant in laboratory medicine

Northamptonshire Area Health Authority

F R N LYNCH, MB, MFCM, community physician are small, this association between overnight accommodation and occurrence of pneumonia is significant at the $8 \%$ level (Fisher's exact test). One member of staff was found to have $L$ pneumophila serogroup 1 antibody at a titre of 128, but neither he nor any other employee gave a history of illness compatible with Legionnaires' disease since taking up employment at the hotel.

In a retrospective search for associated cases occurring in 1979 and early 1980, four other persons with a history of pneumonia developing during a stay at the hotel or within the next week were found. Appropriate specimens taken at the time of illness were available from only one of these, an elderly woman who had stayed at the hotel during the month after the golfers' visit. $L$ pneumophila was shown in her stored lung tissue by direct immunofluorescence staining.

The nine-storey hotel was built about 14 years ago and has 48 bedrooms; it is not airconditioned but has an extract ventilation system for the dining room, kitchens, and bathrooms. During the summer of 1979 small volume water samples of up to a litre were taken from taps, a water storage tank, and other sites in the hotel but $L$ pneumophila was not isolated. Further water samples were collected in October. Serological studies in December on guinea-pigs inoculated with shower water suggested the presence of legionellae. When more samples were taken early in 1980 the organism was isolated from samples of water (ranging from 2 to 25 litres) from two storage tanks, hot and cold water taps, and shower outlets but not from the mains water supply or from tap water in five other buildings nearby. In view of these findings and the association with confirmed cases of Legionnaires' disease, the hotel was closed temporarily for cleaning and chlorination (with 50 parts per million of free chlorine) of its tanks and water distribution system. Subsequently a continuous chlorination unit was installed and is now in operation.

Gas-liquid chromatography studies have since confirmed the identification of $L$ pneumophila. The isolates from samples of water from the hotel have been identified as serogroup 1 strains and the previous serological studies on the patients had indicated that they were infected with strains of $L$ pneumophila of serogroup 1 , the serogroup identified most commonly in cases of Legionnaires' disease in Britain and elsewhere. The only other occasion on which $L$ pneumophila had been isolated in Britain from waterhandling equipment was in 1979 during the investigation of two cases of Legionnaires' disease in a new renal transplant unit. ${ }^{3} L$ pneumophila serogroup 6 was isolated both from the patients and from shower-bath mixers in the transplant unit but not from the water storage tanks.

A recent survey in hospitals and hotels has shown that the bacterium may be found not uncommonly in water systems within buildings though not from mains water supplies. ${ }^{4}$ A history of exposure to water from taps and showers which are shown later to be contaminated with $L$ pneumophila does not, therefore, establish proof of infection from that source. Nevertheless, the fact that the organism had not been isolated from other possible sources or vehicles, particularly in the case of the transplant patients, who were confined to the renal unit during the incubation period, suggests that they were infected by the water either directly or through an aerosolpresumably by inhalation, although the conjunctivae cannot be excluded as a portal of entry. There is now sufficient evidence from the United States ${ }^{5}$ to implicate air-conditioning cooling towers and evaporative condensers in the spread of legionellosis. Recent findings in Britain suggest that on occasion water storage and plumbing systems may act also as sources and vehicles for the spread of $L$ pneumophila

No case of Legionnaires' disease associated with the hotel in the nine months after chlorination has been identified. Throughout the investigation the co-operation of the hotel owners and staff was exceptional. The assistance given by the local environmenta health department and the Anglian Water Authority is also gratefully acknowledged.

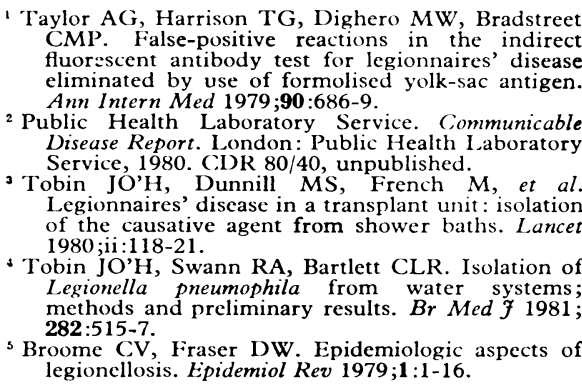

\section{PARLIAMENT}

\section{Private practice and the NHS}

In a short adjournment debate in the House of Commons on 23 January Mr Frank Dobson drew attention to the proposal by the trustees of University College Hospital, London, to hand over control of land adjacent to the hospital, which had been bought to build an extension, to a private profit-making hospita on the site. In exchange for this gift of public property to the private sector the private company would undertake to build operating theatres for the NHS side of UCH. Mr Dobson objected to the scheme because it would be a parasite on the NHS and would attract nursing and ancillary staff from UCH. Furthermore, it was a poor bargain. The promoters of the scheme had estimated that it would cost over f2m to provide the specialty theatres for the NHS. They had also said that if a $95 \%$ bed ratio were achieved in the new hospital it would make $f 2 \mathrm{~m}$ in its first year of operation. "This private profit-making group is therefore doing no more than forgo one year's profit in return for being given public land to exploit in the area." UCH should receive more money from the NHS. The BMA, Mr Dobson said, "not a notorious knocker of the Government or a contributor of funds to the Labour Party, as far as I know," had written to him about the project: "More resources must be devoted to the NHS not just to keep the Service ticking 